\title{
Tributo de los niños y niñas a Violeta Parra: experiencias pedagógicas de lenguajes artísticos
}

\author{
Children's tribute to Violeta Parra: pedagogical experiences of \\ artistic languages
}
Mónica Reyes Ochoa* , Marcos Acevedo Encina** y Raquel Núñez Navarrete***

\begin{abstract}
RESUMEN
El presente texto describe la implementación de un proyecto de vinculación con el medio, realizado en un jardín infantil de la comuna de Peñalolén, en conjunto con un grupo de docentes y estudiantes de la carrera de Educación Parvularia de la Universidad Católica Silva Henríquez, en el marco de la celebración de centenario de la destacada artista chilena Violeta Parra. Su implementación consideró experiencias pedagógicas por medio de los distintos lenguajes artísticos: plástica, danza, música y literatura, a través de los cuales se buscaba visibilizar el aporte de niños y niñas en relación con la resignificación de la obra de la artista en sus propias formas de expresar. Haber realizado este proyecto, en el marco de esta celebración nacional, nos deja muy satisfechos y nos desafía a seguir trabajando para fortalecer la relación de la infancia con el arte, la identidad y la memoria, así como también en la articulación entre la academia y las aulas.
\end{abstract}

Palabras clave: didáctica, didáctica de los lenguajes artísticos, infancia, Violeta Parra.

Educadora de Párvulos, magíster en Investigación Educativa, académica de la Escuela de Educación Parvularia. Contacto: mreyes@ucsh.cl Orcid: https://orcid. org/0000-0003-3560-5598

** Profesor de Estado en Educación General Básica, magíster en Educación, mención Curriculum e Innovaciones Pedagógicas, académico de la Escuela de Educación Parvularia. Contacto: macevedoe@ucsh.cl Orcid: https://orcid.org/0000-0002-2523-2495 *** Profesora de Danza, magíster en Educación, Mención Curriculum e Innovaciones Pedagógicas, magister en Psicomotricidad, académica de la Escuela de Educación Parvularia. Contacto: rnunezn@ucsh.cl Orcid: https://orcid.org/0000-0001-5285-2748 
Tributo de los niños y niñas a Violeta Parra: experiencias pedagógicas de | Reyes Ochoa et al.

\section{SUMMARY}

The present text describes the implementation of a social environment project, carried out in a kindergarten in the Peñalolen district and teachers and students from the Early Childhood Education department of the Silva Henríquez Catholic University 100-year tribute celebration of the outstanding Chilean artist Violeta Parra. Its implementation included pedagogical experiences through different artistic languages: plastic arts, dance, music, and literature. It sought to make children's contribution and expression, in the revising of the artist's work, visible. To have carried out this project, in the framework of this national celebration, leaves us very satisfied and challenges us to continue working to strengthen the relationship of children with art, identity, and memory, as well as in the link between academia and the classroom.
Key words:

didactics, artistic languages, didactics, childhood, Violeta Parra. 


\section{Introducción}

En este texto queremos compartir la experiencia del proyecto "Tributo de los niños y niñas a Violeta Parra", enmarcado en la conmemoración del centenario de la artista en 2017, ocasión que motivó diversas actividades de homenaje en nuestro país. Por lo mismo, un grupo de docentes de la Escuela de Educación Parvularia de la Universidad Católica Silva Henríquez creyó necesario generar un espacio para que los párvulos también pudieran rendir su tributo a tan destacada artista chilena.

A través del trabajo en equipo y en el compartir experiencias y sueños, no quisimos dejar pasar esta oportunidad de relevancia nacional, la que se constituyó en eje de celebración nacional en distintos ámbitos de nuestra cultura.

El interés por fomentar la participación y expresión de niños y niñas obedece, entre otras razones, a que lamentablemente en muchas ocasiones éstos son invisibilizados, limitando así su potencial creativo y constructivo, situación que compartió en el pasado nuestra hoy reconocida mundialmente Violeta Parra. Al respecto es relevante señalar que consideramos a niños y niñas, como platean Dahlberg, Moss y Pence (2005), como co-constructores de conocimiento, de su propia identidad y de cultura desde el inicio de sus vidas.

La adjudicación de recursos de apoyo financiero, a través del concurso de Vinculación con el Medio de nuestra universidad, permitió la implementación del "Proyecto Tributo de los niños y niñas a Violeta Parra". Para ello, docentes de la Escuela Educación Parvularia, desde diversas disciplinas artísticas - música, plástica, danza y literatura, pudieron generar un diálogo entre los párvulos y la obra de Violeta Parra.

Afortunadamente, la comunidad educativa del Jardín Infantil Belén, de la comuna de Peñalolén, muy generosamente nos abrió sus puertas para realizar el proyecto. Se contó con la participaron de aproximadamente 60 párvulos y sus familias, así como también con el apoyo y compromiso del equipo educativo y, muy especialmente, de tres de nuestras estudiantes, quienes se encontraban realizando su práctica profesional en dicho jardín. 
Con relación a la vinculación lograda entre la academia y el aula, a través de la implementación de este proyecto, la directora del Jardín infantil, Sra. Hilda Hormazábal, señaló lo siguiente:

Ha sido muy importante para el proyecto educativo del jardín tomar el desafío propuesto por la universidad de llevar a cabo este proyecto en este establecimiento, y ver que también se han involucrado una amplia gama de profesionales y académicos en las experiencias directas con los niños y niñas en aula. Lo que cobra relevancia es que la academia optó por el contacto directo en el espacio educativo, esto le da un sentido distinto, ya que la diversidad de actores que se involucran e interactúan proporciona una riqueza, pocas veces vista en un proyecto de esta categoría.

Para la implementación del proyecto, durante el primer semestre de 2017 se realizaron variadas experiencias pedagógicas de expresión artística (plástica, música, danza y literatura) con los niños y niñas y el equipo técnico-profesional encargado de los niveles Medio Mayor y Prekínder del Jardín Infantil Belén. Para ello, cada uno de los docentes de la carrera de Educación Parvularia, especialistas en las distintas áreas disciplinares, se trasladó hasta el Jardín Infantil para realizar su propuesta pedagógica con niños y niñas.

En relación con las experiencias pedagógicas realizadas con los párvulos, las estudiantes en práctica compartieron las siguientes reflexiones:

Los niños y niñas participaron activamente del proyecto, y se interesaban cada vez por aprender algo nuevo de esta artista, mostraban entusiasmo y realizaban preguntas constantemente, lo cual me causó asombro, porque nunca imaginé que niños y niñas de esa edad ( 3 a 4 años) se involucrarían tanto con una persona "desconocida" por ellas/os. (Camila Valenzuela)

Fue un trabajo de aprendizaje y significado, tanto para mí como también para los niños y niñas... (Valentina Delbene)

... me dije "ya, ahora sí, al foco de la plástica y música le falta un sentido", y era ahí donde se debería potenciar (la obra de Violeta Parra), con los párvulos. (Cynthia Vásquez) 
Asimismo, se visitó el Museo de Violeta Parra, como una forma de culminar el trabajo pedagógico realizado con los párvulos. El recorrido les permitió observar distintos objetos, principalmente de la obra plástica de la artista.

Cada una de estas visitas contó con el acompañamiento de un equipo de audiovisualistas que fueron registrando las manifestaciones, ideas y gestos de los párvulos en cada uno de los encuentros. Toda esta documentación y registro audiovisual dio origen a un video y una exposición fotográfica, material que fue presentado tanto en el Jardín Infantil como en nuestra universidad, a modo de culminación del proyecto.

Con este proyecto buscábamos principalmente:

- Generar, desde la carrera de educación Parvularia, un espacio para las manifestaciones artísticas de niños y niñas con relación a la resignificación de la obra artística de Violeta Parra en el año de su centenario, en conjunto con instituciones del ámbito de la cultura y la educación.

- Implementar un conjunto de actividades con estudiantes de práctica profesional y académicos de la carrera, para realizar un registro de las distintas manifestaciones de niños y niñas en torno a la obra artística de Violeta Parra.

- Elaborar un material audiovisual y escrito con el registro de expresiones artísticas de niños y niñas, y de las referencias didácticas de las artes en relación con la figura de Violeta Parra.

Por otra parte, y como ya se señaló, a través de este texto se pretende visibilizar el aporte de los párvulos en la conmemoración del centenario de Violeta Parra, como un reconocimiento a la obra de esta artista chilena por parte de las nuevas generaciones. Así como, también y muy particularmente, difundir elementos de la didáctica específica que los docentes especialistas propusieron para el trabajo pedagógico implementado con los párvulos.

Violeta Parra y su obra son un puente para el desarrollo de múltiples experiencias pedagógicas en diferentes ámbitos educativos con los párvulos. Desde varios aspectos de su vida, tanto como artista, recopiladora, investigadora, autora y compositora, y sobre todo como mujer, su obra encierra un gran potencial que, usado en el quehacer 
pedagógico, permite situarnos en lo que fuimos, somos y seremos en lo identitario. Asimismo, a través de la incorporación de los distintos lenguajes artísticos en el proyecto, quisimos favorecer el aprendizaje de los párvulos en ámbitos como el desarrollo de la sensibilidad estética o la capacidad expresiva y creativa. Al respecto, Vecchi (2013) señala que "Cada lenguaje tiene su propia gramática, su carácter específico, pero también tiene una estructura dispuesta para la comunicación y la relación", lo que, en cada una de las experiencias, niños y niñas expresaron, bailando las canciones de Violeta o dibujando aquello por lo que querían dar gracias a la vida, entre otras.

De igual forma, cabe destacar que, con relación a las artes, las Bases Curriculares de la Educación Parvularia (BCEP 2018) proponen el siguiente propósito:

A través de los Lenguajes Artísticos, se espera potenciar en las niñas y los niños, habilidades, actitudes y conocimientos para la expresión creativa de la realidad, y la adquisición de la sensibilidad y apreciación estética. De esta manera, amplían sus posibilidades de percibir, disfrutar y representar tanto su mundo interno como la relación con el entorno cultural y natural, empleando progresivamente diversos medios y recursos.

De este modo, podemos observar que la incorporación de los lenguajes artísticos en el trabajo pedagógico con los párvulos, no solo esta explícitamente señalado en el marco curricular de la Educación Parvularia, sino que también representa una oportunidad para que los párvulos aprendan de su cultura e identidad y contribuyan a la re-significación de estas a través de sus expresiones, ideas y propuestas.

Para ello, se analizan los elementos didácticos presentes en dos de las experiencias implementadas en dicho proyecto: música y danza:

\section{I. Área Música: Una experiencia llena de luz. Profesor: Marcos Acevedo Encina}

A través de esta experiencia, se pretendió generar un espacio de diálogo entre las canciones de Violeta y los párvulos, potenciando el juego musical y experimentando con diferentes recursos, como la voz, el cuerpo, instrumentos musicales y objetos. 


\section{II. Área Danza: Danzando con Violeta profesora: Raquel Núñez Navarrete}

Esta experiencia buscó profundizar y sensibilizar la manifestación del lenguaje corporal, propio de niños y niñas, por medio de las canciones de Violeta Parra, siendo un ámbito en el desarrollo integral e interacción social del ser humano.

Si bien las Bases Curriculares se actualizaron en 2018, la experiencia de aprendizaje que se realizó en el Jardín Belén de Peñalolén fue en contextos de las Bases de 2001. En el Núcleo Lenguajes Artísticos de estas bases se plantea que: "A través de la interacción con el entorno, los lenguajes artísticos se constituyen en instrumentos privilegiados para exteriorizar las vivencias emocionales, desarrollar el pensamiento creativo y disfrutar de manifestaciones culturales y artísticas". Por otro lado,

en este proceso gradual de apropiación y construcción de significados, los niños y las niñas van ampliando y enriqueciendo las posibilidades de representar su mundo interior y su relación con el entorno, lo que les permitirá mayores grados de elaboración, abstracción y simbolización de sus experiencias, sensaciones, sentimientos e ideas.

Objetivos de aprendizaje, Segundo Nivel (Medio), seleccionados para la experiencia. (B.C.E.P. 2001)

1. Manifestar interés por diversas producciones artísticas (arquitectura, modelado, piezas musicales, pintura, dibujos, títeres, obras de teatro, danzas, entre otras), describiendo algunas características.

2. Expresar sus preferencias, sensaciones y emociones relacionadas con diferentes recursos expresivos que se encuentran en sencillas obras visuales (colorido, formas), musicales (fuente, intensidad del sonido) o escénicas (desplazamiento, vestimenta, carácter expresivo).

3. Interpretar canciones y juegos musicales, experimentando con diversos recursos tales como, la voz, el cuerpo, instrumentos musicales y objetos. 


\section{I. Área Música: Una experiencia llena de luz}

En vivencias tempranas de niños y niñas, experiencias con sonidos y en especial con la música pueden potenciar y desarrollar que hagan discriminaciones sonoras sobre la base de la intensidad: sonidos largos y cortos (duración) y las frecuencias altas (agudas), para alcanzar así un modo de encuentro profundo y tranquilizador entre el vínculo de ellas y ellos con sus experiencias específicamente sonoras.

El uso de la música debe entenderse entonces, como vía de comunicación, expresión y crecimiento humano. Concha-Molinarí (2010) nos reafirma diciendo:

el niño, junto con sus compañeros, protagoniza el descubrimiento del entorno sonoro y contribuye a la musicalización del aula y del jardín, al intervenir intuitiva y espontáneamente con su voz, sus movimientos en el espacio, manipulando, digitando, percutiendo, insuflando y agitando objetos sonoros e instrumentos sencillos. (p. 19).

Con ello se logran experiencias significativas y enriquecedoras, tanto para su presente experiencial, como para su futuro relacional.

Por otro lado, el uso de la música, de manera activa y con intencionalidad pedagógica, provoca una activación de la corteza cerebral. Según Concha-Molinari (2010) “toda persona que escucha biológica y fisiológicamente, está capacitada para entender, dar significado y sentido a la música en su subjetivo mundo interior" (p. 21).

La potenciación y el desarrollo en la capacidad de memoria, atención y concentración de los niños, mejora en la habilidad para resolver problemas matemáticos y de razonamiento complejos, estimulación de la creatividad, la imaginación y el lenguaje, son efectos que surgen de esta clase de experiencias: Para Concha-Molinarí (2010), "Todo niño, todas las niñas pueden llegar a transformar lo inconsciente del oir en escucha consciente, en placer significativo, al descubrir y compartir la "belleza sonora" siempre que se hable de ello, se dialogue, se verbalice desde pequeños" (p. 21).

La música fue en sus orígenes un hecho mágico y trascendente para la vida de la sociedad, potenciado por el hecho de que todas las personas tienen la capacidad de percibir, sentir y expresar la música. Por lo tanto, los niños y las niñas vienen con potencialidades que debieran 
ser descubiertas, desarrolladas y activadas en su experiencia educativa más temprana. Según Dalcroze (2017):

El ser humano, desde que nace, posee capacidades físicas que la educación, con bastante frecuencia, no desarrolla de una manera útil. La energía muscular se desarrolla sin control ni objetivos. Los movimientos involuntarios de los músculos obedecen a órdenes que provienen del inconsciente, que tendrán que ser metodizados, evitando así los movimientos que sean innecesarios. Cuando los alumnos tengan el suficiente entrenamiento, deberán poner los movimientos involuntarios de los músculos en favor de una educación compatible con los recursos de los que se disponga. (Dalcroze, 2017, p. 13).

Estas capacidades, que la mayoría de los niños presentan en forma innata, pueden afinarse y perfeccionarse por medio de la educación musical o el uso y potenciación activa de la música con intencionalidad bien precisa; sin embargo, si estas habilidades natas no se estimulan, tienden a atrofiarse hasta desaparecer. Dalcroze (2017) refuerza lo planteado, diciéndonos:

A través del oído podemos descubrir el sonido y el ritmo musical y controlar su percepción. La voz es el medio para reproducir el sonido; nos permite vislumbrar la idea que el oído se ha formado del sonido. Ser consciente del sonido es poder imaginarse, sin la ayuda de la voz y del instrumento, gamas de sonidos, y poder reconocer cualquier melodía y cualquier acorde. Esta capacidad se desarrolla entrenando el oído y la voz. (Dalcroze, 2017, p. 19)

Desde el campo del saber pedagógico, en la Educación Parvularia, es requisito esencial considerar la práctica musical tanto de manera cantada, como en interpretación de instrumentos musicales de percusión y expresividad con el cuerpo en percusiones de palmas, caminando y saltando, como parte de la vida cotidiana en la familia, en las salas cunas, y centros infantiles. Dalcroze (2017) sintetiza: "Para "educar" el ritmo, es necesario entrenar rítmicamente todo el cuerpo" (p. 31). "Los hábitos motrices se adquieren en la edad más temprana" (p.13).

El Ministerio de Educación (MINEDUC), en tanto, señala que: "la exploración del movimiento busca ofrecer a las niñas y niños la posibilidad de conocer, expresar y comunicar a través del cuerpo y su movi- 
miento, consolidando los ya conocidos y permitiendo la indagación y adquisición de nuevos movimientos" (p. 34).

¿Por qué son tan importantes los primeros 5 a 6 años de la vida de un niño? ¿Qué se juega allí? Los primeros diez años de la vida los dividimos en dos fases: la primera infancia hasta los cinco años y, luego, la niñez. Sin embargo, ¿por qué es tan importante la primera infancia? Porque es fundacional, porque entonces se crean todas las redes neuronales que van a ser la base de lo que ocurrirá después: los cimientos del desarrollo cognitivo y socioemocional del niño.

Por esto nos planteamos, como equipo y en especificidad, que en la primera infancia, desde el uso activo de la música (con intencionalidad pedagógica), se instale una propuesta cuyo sustento esté en la experimentación multisensorial y, fundamentalmente, en lo identitario.

Amanda Céspedes (2016) plantea que: "Lo esencial es que el niño viene ya antes de nacer con una red neuronal de soporte, que se desarrolló durante los últimos tres meses del embarazo. Sobre esa red, durante su primera infancia va creando modelos internos sólidos, estables e indelebles, que serán la base de todo lo que vendrá después" (p. 30).

Por ello, entonces, hay que dedicar más tiempo a la música, el arte, los juegos, el movimiento y la creatividad. Una de las grandes perdedoras hoy día es la imaginación y la creatividad. La música ofrece una placentera y provechosa experiencia de aprendizaje y alimenta la imaginación y la creatividad de los niños y niñas. Contreras-Rodríguez (2009) afirma: "Una actividad musical bien intencionada desde su uso, potencia y desarrolla al menos una decena de conductas". Efectivamente, las experiencias musicales potencian y desarrollan, entre otros, estados de concentración; autoestima, afectividad, relajación, oído musical (pulso- acento y ritmo), trabajo en equipo, socialización y juego, motricidad y movimiento, y memoria y conocimientos.

El uso consciente y ejercitación sostenida de los elementos rítmicos básicos (pulso- acento y ritmo) proporcionan al niño los materiales necesarios para una aproximación más amorosa y segura a la práctica de la música. Nos dice Dalcroze (2017), "los latidos del corazón dan, por su regularidad, una idea diáfana del compás": justamente, los conceptos de "pulso" y "acento" contienen implícitamente cualquier melodía, en este caso de la creación de Violeta Parra. 
Usar la música como agente potenciador del aprendizaje es muy distinto de emplearla para fines puramente estéticos o de esparcimiento, como cuando la oímos de sobremesa, a solas en nuestra habitación o en compañía de amigos. No quiere decir esto que no medie necesariamente un aprendizaje significativo al emplear algunas de estas modalidades de escucha; sin embargo, un contexto pedagógico necesariamente precisa contar con algunos puntos de referencia determinados previamente. Es necesario que, en el empleo de la música, se cuente con una estructura definida, consistente en un procedimiento preparado y complementado eficazmente por una retroalimentación continua e inmediata. En otras palabras, el empleo de la música con fines educativos no debe ser un proceso azaroso y desprovisto de una propuesta diseñada con intencionalidad pedagógica.

En el trabajo académico y activo del equipo docente de la carrera de Educación Parvularia UCSH, es relevante dar curso y acción a las ideas que generen opciones y oportunidades de conocimiento en nuestras estudiantes. La actividad específica, considerando y poniendo como eje la obra de Violeta Parra, con niños y niñas en el jardín Belén, no estuvo exenta de aquello.

Considerando lo anterior, desde la asignatura "Expresión musical en el párvulo" se estructuró una experiencia pedagógica con carácter expresivo y participativo, la que fue puesta en marcha y en contexto con las situaciones emergentes propias de una experiencia pedagógica en aula. Hacer este viaje al interior de nuestra identidad, de lo que fuimos, somos y seremos, nos permitió configurar la experiencia desde la obra creativa y musical de Violeta Parra. Al trabajarla con las niñas y niños del Jardín Belén, hubo una aproximación a su obra y a lo que podemos sacar de ella para nutrir la experiencia en aula.

Desde lo que se sabe de su obra como artista, recopiladora, investigadora, autora y compositora, emergen opciones de enseñanzaaprendizaje de valor pedagógico, que fue la motivación central que se concretó en las actividades musicales expuestas y narradas. SepúlvedaLlanos (1983) refuerza esta puesta en marcha diciéndonos lo siguiente:

Otro es el mundo del saber tradicional. Este es el mundo del metabolismo de la infancia, ordenándose a medida del deseo abierto al afán de búsqueda, sin prejuicio ante lo extraordinario, ante lo otro; 
mundo del ser que explora el espesor del mundo sentido de otro modo, que hace el laberinto imaginario del mundo de afuera sabiendo también que es mundo de adentro. (p. 14)

El conocimiento de su obra usada en aula permite concretar el sentido de pertenencia y valor de nuestras tradiciones. Nuestro trabajo como educadores debe orientarse también a la tradición, que no es pasado sino presente, y que está presente en esta oportunidad en la obra de Violeta Parra. Loyola y Cádiz (2010) agregan: "La danza y la canción surgen en su medio natural como fenómenos socioculturales cargados de contenidos o significados que nos llevan a conocer parte de la cultura de una región o país, descubrir el mundo interior de sus protagonistas y el universo que los rodea" (p. 21). Agregaríamos a lo anterior que el repertorio de la tradición folklórica de la infancia y las creaciones, en este caso de Violeta Parra, constituyen herramientas necesarias y trascendentes para la formación de nuestros niños y niñas.

\section{Experiencia de aprendizaje}

\section{Objetivos}

1. Sensibilizar y desarrollar la percepción auditiva y musical expresiva en el contexto de una experiencia multisensorial, usando como medio para ello una composición de Violeta Parra.

2. Escuchar y percutir el pulso, acento y ritmo (elementos rítmicos básicos de la música) de la canción-vals "Que pena siente el alma", cantada por el profesor, con las palmas, palmas en sus muslos, en su pecho, en el piso en repetidas oportunidades. Percutir también con instrumentos de percusión: maracas, triángulos, claves y panderos.

4. Cantar la canción-vals, junto al profesor, caminando y saltando el pulso, acento y ritmo. Realizar la misma actividad con los instrumentos de percusión mencionados.

\section{Actividades}

1. Cantan canciones del repertorio infantil tradicional y folklórico: “Caballito blanco" y "Arroz con leche", y se les invita a jugar (cambiando) 
algunas palabras específicas de los textos de ellas, a modo de juego compartido. Por ejemplo: "Caballito blanco, llévame de aquí" a "Caballito... (colores propuestos), llévame de aquí”; igualmente con la canción "Arroz con leche" a "Arroz con (comida propuesta)".

\section{II. Área Danza: Danzando con Violeta. El movimiento espontáneo en la educación infantil.}

Desde muy pequeños, niños y niñas se comunican con cada movimiento, mirada o simple gesto, como una sonrisa, que quiere decir algo y, a medida que crecen, es más evidente aún. Es importante poner atención a esa forma de interacción, no solo a lo que dicen las palabras cuando comienzan a hablar, sino que, además, a sus primeras manifestaciones corporales.

Por lo mismo, durante su proceso de desarrollo podremos potenciar la interacción de su cuerpo con el medio que le rodea, a través del estudio y utilización intencionada de los gestos, miradas y posturas corporales. El cuerpo, sus posibilidades expresivas y el espacio y el tiempo en los que actúa, constituyen los canales básicos para conferir significado a las acciones humanas.

Schinca (2010) destaca que el profesional, en el ámbito de la técnica y expresión del movimiento, construye un pensamiento de expresividad corporal, manifestando:

...podríamos aseverar que todos los seres humanos enviamos y recibimos mensajes corporales a través del gesto, el modo de movernos y las posturas que adoptamos, incluso aunque no seamos conscientes de ello. Los pensamientos, estados anímicos y emociones se hacen patentes mediante el lenguaje no verbal. La parte física y la parte psíquica están absolutamente entrelazadas, integradas en un todo, los ejemplos más simples son los más fáciles de entender: la ternura hacia alguien provoca un gesto suave, o una determinada expresión del rostro, muy diferente al disgusto o la cólera. Todos los deseos, emociones e ideas se expresan corporalmente, así como las relaciones con los demás. (pp. 12-13)

Como bien comparte la autora, la expresividad del cuerpo va a estar determinada por una actitud psíquica, es un cuerpo que habla, que dialoga con otro, siendo parte del repertorio para el lenguaje corporal. 
Siguiendo el mismo trayecto, Tabak (2017) reflexiona acerca de los beneficios de la expresividad corporal:

...propicia un cambio en las actitudes, en la escucha al propio cuerpo y al de los otros. Se propone facilitar el desarrollo de las cualidades, las habilidades corporales, la autoconciencia y la creatividad. No se basa en copias de modelos, sino en la exploración sobre los propios y cambiaste modos de decir y hacer. (p. 52)

Por lo tanto, durante los tres primeros años de vida de niños y niñas se desarrolla la motricidad, originando la organización de esquemas corporales en los cuales comienzan a descubrirse y a identificarse como personas. Chokler (1998) señala como primeros organizadores al vínculo y al apego, lazos que son primordiales en la construcción relacional del niño con los adultos y que, a su vez, no deben poner en riesgo la exploración autónoma del niño y de la niña.

Dicho lo anterior, para potenciar la exploración autónoma motriz existen diversas esferas del conocimiento, y está comprobado que la expresión corporal estimula el lenguaje, la vista y el oído, así como también se generan beneficios en el organismo, como mayor asimilación de grasas, huesos fuertes, músculos flexibles, etc.

Pero además de esas ventajas, también ha sido demostrado que la expresión corporal ayuda a que la seguridad del niño sea mayor, a que tenga una más alta autoestima y a que sepa relacionarse mejor con sus pares. La privación de movimiento en la temprana infancia puede provocar déficit atencional y otros trastornos emocionales (MINEDUC, 2009).

Es así como, a través del tiempo, se está valorando y considerando la importancia de una educación corporal en los jardines infantiles, viéndose reflejado desde la política pública, por medio de las Bases Curriculares de la Educación Parvularia en el Núcleo de Corporalidad y Movimiento, MINEDUC, 2018:

A través de corporalidad y movimiento, se espera potenciar en las niñas y los niños, habilidades, actitudes y conocimientos que le permitan reconocer y apreciar sus atributos corporales, descubrir sus posibilidades motrices, adquirir una progresiva autonomía para desplazarse y moverse, y que contribuyan a expandir sus procesos de pensamiento, satisfacer sus intereses de exploración, 
fortalecer su identidad, resolver problemas prácticos y expresar su creatividad. De esta manera, ampliarán sus recursos para actuar en el entorno, desarrollando un sentido de autonomía, bienestar, confianza y seguridad. (p. 61)

Sin duda, el Núcleo de Corporalidad y Movimiento (NCM) es un aporte en la infancia temprana, dialogando asimismo con elementos de la psicomotricidad, permitiendo profundizar en las diferentes situaciones de aprendizaje que debe considerar la educadora de párvulos en relación al trabajo con niños y niñas; ahondando en el conocimiento y vivencia del propio cuerpo de los infantes a partir de la realidad física; posibilitando las diversas capacidades de respuestas ante los diferentes estímulos, y manifestándose en los distintos canales expresivos de los pequeños.

Por lo tanto, la oportunidad de profundizar en el conocimiento y vivencia del propio cuerpo permite llegar a descubrirse, a partir de la realidad física, en un encuentro con la esencia individual, con las posibilidades potenciales, con la capacidad de respuestas ante los diferentes estímulos, con los recursos psicofísicos de que se dispone y también con los obstáculos personales que bloquean el libre curso de los distintos canales expresivos.

No se puede dejar de mencionar, además, que el cuerpo en sí mismo es profundo, evidentemente dramático, acusa todo lo que ocurre en el ámbito interno. Es significativo en su gestualidad y movimiento en el espacio. En el caso del arte escénico - ya sea en la danza o en el teatro-, adquiere una mayor importancia, en todas sus dimensiones, puesto que el cuerpo pasa a ser transmisor y tiene un compromiso extracotidiano (Fernández, Núñez y Cifuentes, 2009).

Para comprender los conceptos de "cuerpo" y "movimiento" se presentan algunas acepciones entregadas por autores, quienes dan diferentes definiciones e interpretaciones acerca de lo que se entiende por estas ideas 4 .

Rescatado de la tesis de Magíster en Educación de Núñez, R. (2011) “Reflexionando acerca de la implementación de la expresión corporal con educadoras de párvulos en formación". Documento inédito, UCSH, Santiago, Chile. 


\section{a) Cuerpo}

Calmes (2004), citado en Lira y Rivera, señalan que: "El cuerpo forma parte de la mayoría de los aprendizajes, no solo como enseñanza, sino como instrumento de apropiación con el mundo y, a su vez, constituyen el medio a través del cual incorporan sus aprendizajes" (2006, p. 10). Respecto de lo anterior, Sefchovich y Waisburd (2001, p. 16): "El cuerpo es el instrumento que nos permite participar activamente en la sinfonía de la vida; es emoción y sentimiento, pero también razón y fuente de experiencia, aprendizaje, conocimiento, percepción, intuición y comunicación".

\section{b) Movimiento}

El movimiento está constituido por espacio, tiempo, energía y flujo que, al combinarlos en el espacio tridimensional del cuerpo humano, produce una multiplicidad de cualidades de movimiento (Fernández, Núñez y Cifuentes, 2010, p. 50).

Por otro lado, Scialom, Giromini y Albaret (2017) señalan, desde la mirada del cuerpo, "es pensando como un todo, como una respuesta global al universo, donde no se separa la fisiología de la física, ni el alma del cuerpo, lo que resuelve además el problema de la unión del alma y del cuerpo, puesto que esto se realiza en cada instante de la vida" (p. 229).

Asimismo, estos autores, a partir de la teoría del cuerpo, describen las siguientes categorías que, para efecto de este apartado, es un valioso aporte:

- El cuerpo es por lo que tengo acceso a las cosas (intencionalidad).

- El cuerpo es por lo que hay objetos (el mundo de los objetos).

- El cuerpo es la unidad de todas las orientaciones (esquema corporal).

- El cuerpo está en relación inmediata con el entorno (proxemia).

- El cuerpo hace que la relación con el mundo sea inmediata y no reflexiva: es la conciencia no tética de sí (no se plantea ella misma, no es conciencia de sí).

- El cuerpo es la existencia entera (el sí en el mundo).

- El cuerpo tiene una estructura metafísica: es trascendental puesto que permite descubrir el mundo (p. 229). 
Los conceptos citados implican actitudes que proporcionan la valoración y apreciación de los usos expresivos y comunicativos del cuerpo, y la disposición favorable ante la calidad del trabajo propio. El conocimiento corporal y la utilización de habilidades y destrezas generan confianza en uno mismo y en la autonomía personal, al mismo tiempo que favorecen un aumento del nivel de competencias y de relaciones personales positivas, contribuyendo a la salud mental del niño y la niña. Lo planteado sugiere, además, a la profesional en sala de educación inicial, que efectivamente debe potenciar la afectividad dentro del aula, pero sin coartar las posibilidades, necesidades e intereses de niños y niñas.

Disciplinas afines, como la psicomotricidad educativa, proponen un significativo aporte a la educación inicial, sugiriendo una mirada globalizadora de los aspectos afectivos, motrices e intelectuales de un niño o niña. Dicho estudio, además, aporta en la construcción social de los infantes en sus relaciones interpersonales, con sus pares y con el vínculo con el medio. En este sentido, Hernández (2019) manifiesta que "otros constructivistas destacarán la importancia de los aspectos socioculturales en la construcción del conocimiento del individuo, resaltando cómo el conocimiento se inicia en una interacción social que aporta elementos que luego el individuo internalizará" (p. 13).

Por lo mismo, las diferentes esferas relacionadas desde la psicomotricidad nos señalan que los niños y niñas se relacionan con su impronta corporal, dado que el cuerpo es vehículo para ser, estar, sentir y expresarse en el mundo que lo rodea. El conocimiento del propio cuerpo y las prácticas psicomotrices son un soporte primordial para el desarrollo integral de cada niño y niña, y sirven como eje orientador en la vida y como una base óptima para que puedan integrarse distintos aprendizajes durante la etapa escolar.

Por lo demás, a partir de la primera etapa del desarrollo sensorio motriz (Piaget, 1985), el cuerpo, valiéndose de sus cinco sentidos, recoge información que es recibida en el cerebro y allí es procesada de forma distinta por cada uno de los hemisferios cerebrales. Estas formas diferentes de procesar es lo que se llama "experiencia", la cual es utilizada, reestructurada a diferentes situaciones como "experiencias significativas", modificando hábitos y conductas (Sefchovich y Waisburd, 2001). Asimismo, estas autoras plantean que el hemisfe- 
rio cerebral izquierdo procesa la información de manera concreta, analítica y lógica, y es a través de este proceso que realiza un tipo de aprendizaje cognitivo o intelectual. Pero el hemisferio cerebral derecho aprende de forma intuitiva y construye la percepción del espacio y del cuerpo dentro de él, vinculándolo a las emociones, el afecto, la fantasía y la imaginación.

Por último, retomando el centro de este apartado en el ámbito de la expresividad corporal, es preciso mencionar algunas ideas del concepto de emoción. Tabak (2017) plantea, respecto a las emociones, "el lugar que ocupan las emociones en el comportamiento del niño y la influencia que tienen en el adulto no es un accidente, sino que son reacciones organizadas que tienen una razón de ser" (p. 60).

Asimismo, Wallon, citado en Sanhueza (2017), señala respecto a la emoción:

...es la primera que suelda al organismo con el medio social, pues el tejido de las emociones está hecho del entramado de sus bases neurofisiológicas y de la reciprocidad que asegura los intercambios con el medio. En la emoción y el lenguaje están las claves que dan al hombre sus señas de identidad; emoción y lenguaje tienen raíces biológicas, pero se constituyen y estructuran merced al intercambio social. Es, por tanto, gracias a la emoción y a través de ella como el niño se convierte de ser biológico en ser social. (p. 10).

Se puede inferir, entonces, que lo importante o lo relevante en las diferentes modalidades de expresión corporal, aunque se llegue a ello por diferentes vías, es que todas persiguen un mismo fin: posibilitar a niños y niñas expresar y comunicar sentimientos, emociones e ideas, a partir de sus diferentes experiencias y su contexto familiar.

\section{La expresión corporal en la formación de educadoras de párvulos}

Desde los inicios, la labor de profesora de danza está presente con niños y niñas, considerando, como elemento de construcción y como potenciador del aprendizaje activo, la corporalidad y el movimiento.

Por lo mismo, la oportunidad de conectarse nuevamente con un espacio educativo como el Jardín Belén ha sido significativa y también una instancia para validar el trabajo corporal como una estrategia que 
favorece, desde una mirada global, los diferentes ámbitos de niños y niñas: cognitivo, afectivo y motriz.

La experiencia de aprendizaje se situó en explorar la libre expresión corporal de los niños y niñas, teniendo como fuente de inspiración a una mujer chilena, referente en la cultura, la historia y el arte: Violeta Parra.

Para los lectores, es importante mencionar que Violeta escribió y compuso música para montajes coreográficos. En 1957, para la obra $E l$ Gavilán, un proyecto ambicioso, proyectó un ballet folclórico en tres momentos, sobre amor y desamor. Pero la idea no culminó, por los hechos nefastos conocidos.

Dicho lo anterior, sin duda Violeta motiva para la indagación rítmico-corporal en el trabajo con la temprana infancia. La experiencia pedagógica en el jardín Belén fue relevante en lo particular, al observar la dulzura y espontaneidad que expresaban los pequeños sabios con relación a su expresividad. Por lo mismo, durante la visita se propuso trabajar con un pañuelo, para que exploraran su creatividad, sus movimientos y buscaran su propio lenguaje corporal, instancia que, sin duda, permitió enriquecer, vivenciar y explorar con los niños y niñas.

La expresión corporal es un recurso emergente en nuestro país, que posee y entrega beneficios a los infantes, tanto en el plano cognitivo como en el social y emocional. Al observar los planes de la educación, que nos presentan un currículo polisémico y dinámico, que va a formar ciudadanos con identidad, lo que se reflejará en la construcción del país, nos encontramos con programas de lenguaje artístico que constituyen el primer acercamiento en el ámbito corporal en la educación de párvulos, pretendiendo a futuro formar a un estudiante independiente, autónomo, que tenga valores y desarrolle su pensamiento individual, generando instancias de introspección para conectarse como ser humano.

El desarrollo de la expresión creativa debe ser un objetivo de la educación; la creatividad es un recurso, un instrumento valioso, y todos nacemos potencialmente creadores. Las metas desde la expresividad corporal buscan tomar conciencia de cómo están los segmentos corporales, de aprender a vivir con el propio cuerpo y la autoimagen, a conectar la sensibilidad, el flujo y la energía que animan el cuerpo. 
Gubbay y Kalmar (2017) señalan respecto de la investigación corporal:

Cada persona tiene un singular lenguaje de movimiento que es honrado y respetado en clases. Valorando aquello con lo que las personas cuentan. Pensamos que lo que define a la persona que baila no es el cuerpo. El foco está en la sensibilización respecto al propio cuerpo y al del otro, y en la capacidad asombrosa de comunicación que tenemos los seres humanos, que trasciende y va más allá de las diferencias. (p. 30).

Actualmente, la educación chilena está en constante cambio y, teniendo en consideración lo planteado, se hace necesario seguir fortaleciendo el crecimiento pedagógico de niños y niñas con una mirada más integral.

Sin embargo, esta es una disciplina poco desarrollada, y es posible que esto se deba a que un número no menor de universidades públicas y privadas no contemplan en sus mallas curriculares actividades que incorporen esta disciplina como tal, inhibiendo la aplicación pedagógica de ésta en los centros educativos por parte de los profesionales egresados.

No obstante, la carrera de Educación Parvularia de la Universidad Católica Silva Henríquez ha querido contribuir en la etapa de formación inicial de sus futuras educadoras de párvulos con el trabajo corporal y expresivo. En la experiencia educativa en el Jardín Belén de la comuna de Peñalolén participaron tres estudiantes en práctica profesional, constatando que es vital seguir otorgando actividades pedagógicas con un sentido más humano y social, reflejándose esto en el trabajo realizado desde el sentir y el pensar de lo que le ocurre al cuerpo del niño y la niña cuando se expresa en un momento cotidiano de la vida.

La Escuela de Educación Parvularia UCSH, imparte dos especializaciones "Atención Temprana” y "Expresión y Creatividad en el párvulo", esta última propone diferentes optativos que desarrollan el trabajo corporal y creativo de las futuras educadoras de párvulos.

La pedagogía de la disciplina de la expresión corporal se preocupa de dilucidar la manera en que aprenden niños y niñas a través del cuerpo y cómo enseñarlo. El trabajo en los optativos de expresión corporal ha sido objeto de posteriores líneas de investigación, siendo un aporte a la propia especialización y estableciendo como su objetivo situar a 
la futura egresada de la carrera en el desarrollo y sensibilización del lenguaje corporal en el primer y segundo ciclo de párvulos, diseñando actividades para potenciar su capacidad creativa y de comunicación, considerando la imaginación y la transformación de las inquietudes, ideas y sentimientos que manifiesten.

El cuerpo debe ocupar un lugar central en el proceso educativo, aunque, históricamente, no ha tenido la atención debida. Es necesario entonces continuar fortaleciendo estos ámbitos, de modo que sean útiles para la formación de seres humanos íntegros. En este sentido, la experiencia vivida en el Jardín Belé fue de reencontrarse con la manifestación expresiva espontánea de niños y niñas, siendo un aporte para fortalecer la tarea de la docencia, resignificando la corporalidad como estrategia pedagógica.

El gesto, la sonrisa y la alegría de moverse y jugar de los niños y niñas durante la realización del taller fue sin duda una inyección de amor para continuar como pedagoga en este camino educativo. Se suma que el equipo del Jardín Belén manifiesta un compromiso con los aspectos sociales y humanos de los párvulos, viéndose esto reflejado en la colaboración con cada taller que se llevó a cabo. En lo particular, en el taller de danza fueron partícipes del proceso de sensibilización, aportando con una actitud corporal, dando seguridad a los niños y con una empatía a la belleza natural de su propio movimiento.

La oportunidad de trabajar en el Jardín Belén enseña que hay que aprender a escuchar los cuerpos, que cada uno tiene su propia impronta corpórea. El cuerpo va a hablar por sí solo si lo invitamos a conectarse con alguna experiencia de agrado o desagrado en un nivel de sensación.

Las intención es destacar la importancia de la expresividad motriz en la educación inicial, para potenciar actitudes y habilidades creativas, expresivas y corporales, abriendo y descubriendo vías para que niños y niñas se transformen y sean mejores personas en un futuro.

\section{Experiencia de aprendizaje}

Logros de aprendizaje (2) B.C.E.P: Disfrutar y experimentar el bienestar que produce la actividad física al ejercitar su esquema corporal y definir su lateralidad, de modo de ser crecientemente competente en 
su actuar. (3). Identificar algunas de sus capacidades para realizar diferentes acciones y llevar a cabo proyectos en los que las aplica.

\section{Situación de aprendizaje:}

Realizar un círculo con los niño/as, preguntando ¿cómo está el cuerpo hoy? Invitar a los niños/as a mover las distintas partes del cuerpo (cabeza, hombro, cadera, piernas, pies).

Luego, en la misma ronda, se expresan libremente con su movimiento (música de fondo, Violeta).

Se les invitará, por medio del pañuelo, a moverse.

Se creará una breve secuencia de movimiento.

Para finalizar, se les invita por pequeños grupos a mostrar sus movimientos con el pañuelo.

Acciones básicas de 1@s niñ@s: Identificar segmentos corporales. Movimiento libre espontáneo. Moverse por el espacio, ocupando el arriba, abajo, al lado, movimientos largos, cortos, rápidos o lentos. Memoria corporal, reconocer la secuencia de movimiento y repetir.

Expresión corporal con el pañuelo.

Recursos didácticos: Música de Violeta, pañuelos de colores.

\section{Conclusiones}

Luego de haber culminado este viaje a la memoria, la expresión y el arte, a través de la obra de Violeta Parra y en conjunto con los párvulos, hemos querido plasmar, mediante este texto, la experiencia de vinculación entre la universidad y el centro educativo, así como entre los párvulos y Violeta Parra, como una forma de contribuir a la memoria y rescate de valor cultural y educativo, que permita a las nuevas generaciones, niños y niñas, conocer no solo el aporte artístico, sino también identitario, a través del reconocimiento del mundo campesino y entorno vivencial, con sus fortalezas y desafíos, presente en la obra de Violeta Parra.

La experiencia implementada con los párvulos a través del proyecto "Tributo de los niños y niñas a Violeta Parra" permitió a la Escuela de Educación Parvularia acercar y poner a disposición de las aulas de un jardín infantil los conocimientos y estrategias didácticas de las 
distintas disciplinas que conforman los lenguajes artísticos - en este caso, la música y la danza-, generándose así un diálogo entre los párvulos y la obra artística de nuestra querida Violeta Parra. Los niños y niñas pudieron conocer a esta artista, dibujando, pintando, cantando o danzando alguna de sus creaciones. Los educadores creemos muy relevante que las nuevas generaciones la conozcan desde la infancia y que, además, se transforme en vehículo y alternativa de innovadoras experiencias educativas en todos los centros educativos.

Desde la danza y la música, las experiencias pedagógicas fueron plasmadas en un registro audiovisual y fotográfico que quedó a disposición del Jardín infantil y de la universidad, como muestra de la participación de los niños y niñas en lo que fue la celebración del centenario de Violeta Parra.

Sin duda, la participación de educadoras, técnicos en párvulos, familia, académicos y equipos directivos de las respectivas instituciones facilitó la implementación del proyecto, lo que muestra una vez más la importancia de vincular la academia y las aulas, permitiendo potenciar y desarrollar en forma activa y participativa los aprendizajes de los distintos involucrados, pero sobre todo de niños y niñas. Sin embargo, esto representa a la vez un desafío mayor, teniendo en cuenta que se requieren tanto recursos humanos como económicos para hacer posible esta vinculación.

Valoramos de manera muy importante la posibilidad de haber facilitado el diálogo entre la infancia y las artes, particularmente en un contexto en que, por una parte, son escasos los espacios que se brindan para visibilizar las distintas expresiones de la infancia, la que, con su opinión, disposición y formas particulares de expresión, se apropió de la obra de Violeta Parra; y, por otra, existe poco lugar para las artes en las aulas, privilegiando algunos contenidos por sobre otros, como son el lenguaje y la matemáticas, los que, sin embargo, se deben complementar con otras disciplinas, para permitir el despliegue de todo el talento y el interés de niños y niñas.

\section{Referencias bibliográficas}

Céspedes, A. (2007). Cerebro, inteligencia y emoción. Neurociencias aplicadas a la educación permanente. Santiago de Chile: Fundación Mírame. 
Chokler, M. (1998). Los organizadores del desarrollo psicomotor. Buenos Aires: Ediciones Cinco.

Dahlberg, G., Moss, P. y Pence A. (2005). Mas allá de la calidad de la educación infantil. España. Edit. Graó.

Dalcroze, E. J. (2017). Rítmica y creación. Gesto, movimiento y forma. Madrid: Ediciones La Pajarita de Papel.

Fernández, R., Núñez, R. y Cifuentes, M. (2010). La eukinética: profundizando las cualidades del movimiento. Santiago de Chile: Editorial La Vieja Ciudad.

Gardner, H. (2001). Estructuras de la Mente. La teoría de las Inteligencias Múltiples. III Reimpressión. México: Fondo de Cultura Económica.

Gubbay, M. y Karmar, D. (2017). El movimiento en la educación. Buenos Aires: Ediciones Novedades Educativas.

Hernández, A. (2019). Construir el bienestar psicológico a través de la psicomotricidad. Revista Iberoamericana de Psicomotricidad y Técnicas corporales, (44), 6-25.

Loyola, M. y Cádiz, O. (2010). La cueca: Danza de la vida y de la muerte. Valparaíso: Ediciones Universitarias de Valparaíso.

Ministerio de Educación. (2001). Bases Curriculares de la Educación parvularia. Santiago de Chile: MINEDUC.

Ministerio de Educación. (2018). Bases curriculares de la educación parvularia. Santiago de Chile: MINEDUC.Ministerio de Educación. (2007). Cantando la infancia, Chile y la tierra americana. Antología poética de Gabriela Mistral para niñas y niños de cuatro a seis años de edad. Santiago de Chile: Unidad de Educación Parvularia, División de Educación General.

Piaget, J. (1985). La construcción de lo real en el niño. Barcelona: Editorial Crítica.

Sanhueza, J. (2017). Introducción a la obra Walloniana, documento inédito no publicado, Programa de Magíster, Santiago de Chile, Universidad Finis Terrae.

Scialom, P., Giromini, F. y Albaret, J. (2017). Manual de estudio en psicomotricidad. España: Fundación CITAP.

Shinca, M. (2010). La expresión corporal: técnica y expresión del movimiento. (4ta edición). España: Editorial Cisspraxis.

Sefchovich, G. y Waisburd, G. (2001). Expresión corporal y creatividad. México: Editorial Trillas. 
Sepúlveda, F. (1983). Notas para una estética del folklore. Revista Aisthesis, 15.

Stokoe, P. (1994). La expresión corporal en el jardín de infantes. España: Editorial Paidós.

Tabak. G. (2017). Explorar el cuerpo en el jardín maternal. Buenos Aires: Ediciones Novedades Educativas.

Vecci V. (2013). Arte y Creatividad en Reggio Emilia. Madrid: Ediciones Morata. 